\title{
A New Pentacyclic Triterpenoid Glucoside from Prunus serrulata var. spontanea
}

\author{
Hyun Ah Jung, ${ }^{a}$ Hae Young Chung, ${ }^{b}$ Jee H. Jung, ${ }^{b}$ and Jae Sue ChOI ${ }^{*, a}$ \\ ${ }^{a}$ Faculty of Food Science and Biotechnology, Pukyong National University; Busan 608-737, Korea: and ${ }^{b}$ College of \\ Pharmacy, Pusan National University; Busan 609-735, Korea. Received September 9, 2003; accepted October 27, 2003
}

\begin{abstract}
A new triterpenoid, $2 \alpha, 3 \alpha, 24$-trihydroxyurs-12-en-28-oic acid-28- $O$ - $\beta$-D-glucopyranosyl ester (4) along with four known triterpenoids, ursolic acid (1), $2 \alpha$-hydroxyursolic acid (2), $2 \alpha, 3 \alpha, 24$-trihydroxyurs-12-en-28-oic acid (3), and $2 \alpha, 3 \alpha, 19 \alpha, 24$-tetrahydroxyurs-12-en-28-oic acid-28- $O$ - $\beta$-D-glucopyranosyl ester (5), were isolated from

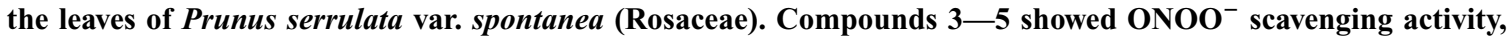
whereas compounds 1 and 2 were virtually inactive.
\end{abstract}

Key words Prunus serrulata var. spontanea; Rosaceae; triterpenoids; $2 \alpha, 3 \alpha, 24$-trihydroxyurs-12-en-28-oic acid-28-O- $\beta$-D-glucopyranosyl ester; $\mathrm{ONOO}^{-}$scavenging activity

Plants of the genus Prunus have been used in indigenous medicine such as sedative, anti-inflammatory, anti-hyperlipidemic, and anti-tumor agents. ${ }^{1)}$ Prunus serrulata var. spontanea (Rosaceae) is a large sized tree widely distributed throughout Korea and Japan. The red fruits are edible and are used in traditional folk medicine against heart failure from beriberi, dropsy, mastitis, toothache, and as an emmenagogue. ${ }^{2)}$ Also, the bark of $P$. serrulata var. sponatenea, $P$. yedoensis, and $P$. sargentii, so called Pruni Cortex, have been used for detoxification and relaxation, and as an antitussive in traditional Korean medicine. ${ }^{3)}$ Previously we reported the antioxidant effect of some selected Prunus genus in terms of scavenging potential of DPPH radical, total ROS, and $\mathrm{ONOO}^{-}$. Among those, the methanolic extract of the leaves of $P$. serrulata var. spontanea exhibited a strong antioxidant activity and afforded antioxidative principles, such as quercetin, kaempferol 3-O- $\alpha$-arabinofuranoside, kaempferol 3-O- $\beta$-xylopyranoside, kaempferol 3-O- $\beta$-glucopyranoside, and quercetin 3-O- $\beta$-glucopyranoside. ${ }^{4)}$

There have been some reports on the isolation of triterpenoids from the Prunus species such as $P$. dulcis, ${ }^{5)}$ P. amygdalus,${ }^{6)}$ P. persica ${ }^{7)}$ and $P$. africana ${ }^{8)}$ No detailed chemical studies as well as biological activities on triterpenoids of $P$. serrulata var. spontanea, however, have been reported. Here we report the isolation and structural elucidation of five compounds $(\mathbf{1}-\mathbf{5})$ from the leaves of this plant.

Column chromatography of the EtOAc soluble part of the methanolic extract from the leaves of $P$. serrulata var. spontanea yielded compounds $\mathbf{1}-\mathbf{5}$ in the order of increasing polarity (Fig. 1). The structures of $\mathbf{1}-\mathbf{3}$ were identified by com-

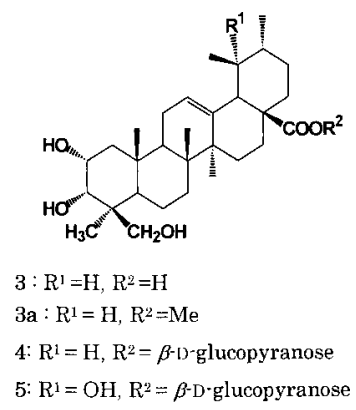

Fig. 1. Chemical Structures of Compounds $\mathbf{3}-\mathbf{5}$ parison of their spectral data as ursolic acid, $2 \alpha$-hydroxy ursolic acid and $2 \alpha, 3 \alpha, 24$-trihydroxyurs-12-en-28-oic acid, respectively. ${ }^{5,9,10)}$ Further detailed analysis of the ${ }^{1} \mathrm{H}$ - and ${ }^{13} \mathrm{C}-$ NMR spectra (Tables 1, 2), aided by DEPT, HMQC, HMBC, COSY and NOESY experiments, confirmed the structure of 3. Methylation with $\mathrm{CH}_{2} \mathrm{~N}_{2}$ of $\mathbf{3}$ gave a 3a, which was characterized as methyl $2 \alpha, 3 \alpha, 24$-trihydroxyurs-12-en-28-oic acid, further supported by direct comparison of their spectral data with those reported. ${ }^{11}$

Compound 4 was obtained as white amorphous powder, and showed a positive reaction in Liebermann-Burchard and Molisch tests. The molecular formula of $\mathbf{4}$ was determined as $\mathrm{C}_{36} \mathrm{H}_{58} \mathrm{O}_{10}$ based on the NMR and high resolution (HR)-FAB-MS data $\left\{[\mathrm{M}+\mathrm{Na}]^{+}, \mathrm{m} / \mathrm{z}: 673.3925\right.$ Calcd for $\mathrm{C}_{36} \mathrm{H}_{58} \mathrm{O}_{10} \mathrm{Na} m / z$ : 673.3928, $\Delta-0.3 \mathrm{mmu}$. The IR spectrum showed a characteristic absorption attributable to an ester carbonyl group at $1735 \mathrm{~cm}^{-1}$, a broad absorption due to hydroxyl group at $3423 \mathrm{~cm}^{-1}$, as well as glycosidic linkage at $1074 \mathrm{~cm}^{-1}$. The ${ }^{13} \mathrm{C}-\mathrm{NMR}$ spectrum (Table 2) of compound 4 showed, in addition to 30 signals consistent with a triterpenoid structure of 3 , six peaks in the range at $\delta 62-96$

Table 1. ${ }^{1}$ H-NMR Spectral Data of Compounds $\mathbf{3}-\mathbf{5}$

\begin{tabular}{llll}
\hline \hline Position & \multicolumn{1}{c}{$\mathbf{3}$} & \multicolumn{1}{c}{$\mathbf{4}$} & \multicolumn{1}{c}{$\mathbf{5}$} \\
\hline $\mathrm{H}-2 \beta$ & $4.41 \mathrm{dt}(10.0,3.9)$ & $4.45 \mathrm{dt}(4.0,11.6)$ & $4.44 \mathrm{dt}(10.0,2.0)$ \\
$\mathrm{H}-3 \beta$ & $4.56 \mathrm{~d}(2.4)$ & $4.57 \mathrm{br}\left(\mathrm{w}_{1 / 2}=6\right)$ & $4.58 \mathrm{~d}(2.0)$ \\
$\mathrm{H}-12$ & $5.44 \mathrm{~s}$ & $5.41 \mathrm{~s}$ & $5.51 \mathrm{~s}$ \\
$\mathrm{H}-18$ & $2.59 \mathrm{~d}(11.2)$ & $2.49 \mathrm{~d}(11.3)$ & $2.89 \mathrm{~s}$ \\
$3 \mathrm{H}-23$ & $1.66 \mathrm{~s}$ & $1.65 \mathrm{~s}$ & $1.64 \mathrm{~s}$ \\
$\mathrm{H}_{\mathrm{A}}$ and & $3.79 \mathrm{~d}(10.9)$ & $3.80 \mathrm{dd}(10.9,16.0)$ & $3.81 \mathrm{~d}(10.8)$ \\
$\mathrm{H}_{\mathrm{B}}-24$ & $4.08 \mathrm{~d}(10.9)$ & $4.10 \mathrm{dd}(5.2,16.0)$ & $4.11 \mathrm{~d}(11.1)$ \\
$3 \mathrm{H}-25$ & $0.98 \mathrm{~s}$ & $1.03 \mathrm{~s}$ & $1.05 \mathrm{~s}$ \\
$3 \mathrm{H}-26$ & $1.01 \mathrm{~s}$ & $1.14 \mathrm{~s}$ & $1.18 \mathrm{~s}$ \\
$3 \mathrm{H}-27$ & $1.11 \mathrm{~s}$ & $1.11 \mathrm{~s}$ & $1.59 \mathrm{~s}$ \\
$3 \mathrm{H}-29$ & $0.91 \mathrm{~d}(6.4)$ & $0.86 \mathrm{~d}(5.2)$ & $1.04 \mathrm{~d}(6.3)$ \\
$3 \mathrm{H}-30$ & $0.94 \mathrm{~d}(6.4)$ & $0.89 \mathrm{~d}(6.5)$ & $1.36 \mathrm{~s}$ \\
$\mathrm{Glu}-1^{\prime}$ & & $6.24 \mathrm{~d}(8.0)$ & $6.26 \mathrm{~d}(8.1)$ \\
$2^{\prime}$ & & $4.18 \mathrm{~m}$ & $4.20 \mathrm{~m}$ \\
$3^{\prime}$ & & $4.27 \mathrm{~m}$ & $4.28 \mathrm{~m}$ \\
$4^{\prime}$ & & $4.35 \mathrm{~m}$ & $4.32 \mathrm{~m}$ \\
$5^{\prime}$ & & $4.00 \mathrm{~m}$ & $4.02 \mathrm{~m}$ \\
$6^{\prime}$ & & $4.37 \mathrm{dd}(4.6,12.0)$ & $4.36 \mathrm{dd}(4.5,12.0)$ \\
& & $4.44 \mathrm{dd}(4.0,11.6)$ & $4.45 \mathrm{dd}(2.0,12.0)$ \\
\hline
\end{tabular}

${ }^{1} \mathrm{H}$-NMR data was measured in pyridine- $d_{5}$ at $400 \mathrm{MHz}$, and the coupling constants ( $J$ values) are presented as $\mathrm{Hz}$ except for $\mathrm{w}_{1 / 2}$ values in br. 
Table 2. ${ }^{13} \mathrm{C}-\mathrm{NMR}$ Spectral Data of Compounds $\mathbf{3}-\mathbf{5}$

\begin{tabular}{|c|c|c|c|}
\hline Carbon No. & 3 & 4 & 5 \\
\hline 1 & 43.2 & 43.3 & 43.2 \\
\hline 2 & 66.2 & 66.2 & 66.3 \\
\hline 3 & 74.2 & 74.2 & 74.2 \\
\hline 4 & 45.1 & 45.1 & 45.2 \\
\hline 5 & 49.4 & 49.4 & 49.5 \\
\hline 6 & 18.8 & 18.9 & 19.1 \\
\hline 7 & 34.0 & 34.0 & 34.0 \\
\hline 8 & 40.2 & 40.4 & 40.8 \\
\hline 9 & 48.1 & 48.1 & 47.9 \\
\hline 10 & 38.5 & 38.5 & 38.6 \\
\hline 11 & 23.8 & 23.9 & 24.4 \\
\hline 12 & 125.5 & 126.0 & 128.4 \\
\hline 13 & 139.2 & 138.4 & 139.2 \\
\hline 14 & 42.7 & 42.5 & 42.1 \\
\hline 15 & 28.6 & 28.6 & 29.2 \\
\hline 16 & 24.9 & 24.6 & 26.1 \\
\hline 17 & 48.0 & 48.3 & 48.6 \\
\hline 18 & 53.5 & 53.3 & 54.4 \\
\hline 19 & 39.4 & 39.3 & 72.7 \\
\hline 20 & 39.4 & 39.1 & 42.1 \\
\hline 21 & 31.1 & 30.8 & 26.7 \\
\hline 22 & 37.4 & 36.8 & 37.7 \\
\hline 23 & 23.8 & 23.8 & 23.8 \\
\hline 24 & 65.2 & 65.2 & 65.2 \\
\hline 25 & 17.2 & 17.3 & 17.2 \\
\hline 26 & 17.3 & 17.6 & 17.4 \\
\hline 27 & 23.8 & 23.7 & 24.5 \\
\hline 28 & 179.9 & 176.2 & 177.1 \\
\hline 29 & 21.4 & 21.2 & 16.7 \\
\hline 30 & 17.4 & 17.3 & 27.0 \\
\hline Glu-1' & & 95.7 & 95.8 \\
\hline $2^{\prime}$ & & 74.0 & 74.0 \\
\hline $3^{\prime}$ & & 78.9 & 78.9 \\
\hline $4^{\prime}$ & & 71.2 & 71.2 \\
\hline $5^{\prime}$ & & 79.2 & 79.2 \\
\hline $6^{\prime}$ & & 62.3 & 62.4 \\
\hline
\end{tabular}

${ }^{13} \mathrm{C}$-NMR data measured in pyridine- $d_{5}$ at $100 \mathrm{MHz}$.

$(95.7,74.0,78.9,71.2,79.2,62.3)$ corresponding to the presence of a glucose moiety. Alkaline hydrolysis of $\mathbf{4}$ afforded $1 \mathrm{~mol}$ of D-glucose along with $\mathbf{3}$ as the aglycon. Thus, compound 4 was shown to be a monoglucoside of 3 . The common D-configuration for glucose was assumed according to this most often encountered among the plant glycosides. The anomeric proton signal at $\delta 6.24(J=8.0 \mathrm{~Hz})$ in the ${ }^{1} \mathrm{H}-\mathrm{NMR}$ spectrum indicated the $\beta$-configuration for the glucopyranosyl moiety. The glycosidic linkage site of $\beta$-D-glucose was determined to be $\mathrm{C}-28$ based on the HMBC spectrum. In the HMBC experiment, the anomeric proton peak at $\delta 6.24$ correlated with the carboxyl group of the aglycone at $\delta$ 176.2. Cmpound 4 was therefore determined as $2 \alpha, 3 \alpha, 24$-trihydroxyurs-12-en-28-oic acid-28- $O$ - $\beta$-D-glucopyranosyl ester. This is the first report of its occurrence in nature.

Compound $\mathbf{5}$ was assigned a molecular formula of $\mathrm{C}_{36} \mathrm{H}_{58} \mathrm{O}_{11}$, established by the positive-ion FAB-MS $(\mathrm{m} / \mathrm{z} 689$ $\left.[\mathrm{M}+\mathrm{Na}]^{+}\right)$as well as ${ }^{13} \mathrm{C}-\mathrm{NMR}$ spectral data and DEPT experiments. Analysis of ${ }^{1} \mathrm{H}$ - and ${ }^{13} \mathrm{C}-\mathrm{NMR}$ spectra (Tables 1 , 2 ) indicated that its structure is quite similar to those of 4 except that it has a singlet at $\delta 2.89$, the characteristic signal for H-18 of ursane triterpenoid with $19 \alpha$-hydroxyl substitution. Substitution of the hydroxyl group at $\mathrm{C}-19$ was also deduced by the appearance of signal at $\delta 72.7$ in the ${ }^{13} \mathrm{C}$-NMR spectrum. The signal of $\mathrm{H}-2$ was observed as a doublet of triplets with the coupling constants of 10.0 and $2.0 \mathrm{~Hz}$, respectively, which indicated a diaxial and two axial-equatorial couplings. Thus, the configurations of both 2 and OH-3 groups were defined as $\alpha$. The nOe observed between $\mathrm{H}-2$ and $\mathrm{CH}_{3}-25$ further supported this stereochemical assignment. Thus, compound 5 was determined to be $2 \alpha, 3 \alpha, 19 \alpha, 24$-tetrahydroxyurs-12-en-28-oic acid-28- $O$ - $\beta$-D-glucopyranosyl ester. Although compound 5 was previously isolated from Rubus xanthocarpus, ${ }^{12)}$ their spectral data of $\mathrm{H}-2 \beta, \mathrm{H}-3 \beta$, and C-3 at $\delta$ $3.83(\mathrm{~m}), 3.57$ (br s), and 78.9, respectively, were not superimposed on our data at $\delta 4.44(\mathrm{dt}, J=10.0,2.0 \mathrm{~Hz}), 4.58(\mathrm{~d}$, $J=2.0 \mathrm{~Hz}$ ), and 74.2 .

Compounds 3 and $\mathbf{5}$ showed high $\mathrm{ONOO}^{-}$scavenging activities with $\mathrm{IC}_{50}(50 \%$ inhibition concentration) $4.90 \pm$ $0.38 \mu \mathrm{M}$ and $6.88 \pm 0.46 \mu \mathrm{M}$, respectively (positive control, penicillamine, $\left.\mathrm{IC}_{50} 5.11 \pm 0.23 \mu \mathrm{M}\right)$. Compound 4 showed moderate activity with $\mathrm{IC}_{50} 82.05 \pm 2.80 \mu \mathrm{M}$, whereas compounds $\mathbf{1}$ and $\mathbf{2}$ virtually inactive.

\section{Experimental}

General The IR spectrum was taken with a Shimadzu FT-IR spectrometer in $\mathrm{KBr}$ disc. The positive-ion LR- and HR-FAB-MS data were collected on a JEOL JMS-HX110/110A spectrometer. The ${ }^{1} \mathrm{H}$ - and ${ }^{13} \mathrm{C}-\mathrm{NMR}$ spectra were recorded on a Varian UNITY-400 spectrometer $\left(400 \mathrm{MHz}\right.$ for ${ }^{1} \mathrm{H}$ and $100 \mathrm{MHz}$ for ${ }^{13} \mathrm{C}$ ). All isolated compounds were measured in pyridine- $d_{5}$. Chemical shifts were referenced to the respective residual solvent peaks $\left(\delta_{\mathrm{H}}\right.$ $7.19,7.56,8.70$ and $\delta_{\mathrm{C}} 123.5,135.5,149.5$ for pyridine- $d_{5}, \delta_{\mathrm{H}} 7.26$ and $\delta_{\mathrm{C}}$ 77.0 for $\mathrm{CDCl}_{3}$ ). COSY, NOESY, HMQC, and HMBC spectra were recorded using pulsed field gradients. Column chromatography was performed with Si gel (Merck, 70-230 mesh), Sephadex LH-20 and Sep-Pak PLUS C18. The TLC was performed on a pre-coated Merck Kieselgel 60 $\mathrm{F}_{254}$ plate $(0.25 \mathrm{~mm})$ and $50 \% \mathrm{H}_{2} \mathrm{SO}_{4}$ was used as spray reagent.

Chemicals The DL-penicillamine (DL-2-amino-3-mercapto-3-methylbutanoic acid) was purchased from the Sigma Chemical Company (St. Louis, MO, U.S.A.). The DHR 123 (dihydrorhodamine 123), and peroxynitrite were obtained from Molecular Probes (Eugene, Oregon, U.S.A.) and Cayman Chemicals Co. (Ann Arbor, MI, U.S.A.), respectively.

Plant Materials The leaves of $P$. serrulata var. spontanea were collected at Gumjung mountain, Busan, Korea in April 1999, and authenticated by Dr. Maeng Ki Kim, Korea Environmental and Ecological Services, Busan, Korea. A voucher specimen has been deposited in the Herbarium of the Medicinal Plant Garden, College of Pharmacy, Pusan National University, Busan, Korea.

Extraction, Fractionation, and Isolation The dried leaves of $P$. serrulata var. spontanea $(1.8 \mathrm{~kg})$ were refluxed with methanol $(\mathrm{MeOH})$ for $3 \mathrm{~h}$. The total filtrate was concentrated and dried in vacuo at $40{ }^{\circ} \mathrm{C}$ to render the $\mathrm{MeOH}$ extract $(471 \mathrm{~g})$. The extract was suspended in water $\left(\mathrm{H}_{2} \mathrm{O}\right)$ and sequentially partitioned with dichloromethane $\left(\mathrm{CH}_{2} \mathrm{Cl}_{2}\right)$, ethyl acetate (EtOAc), and $n$-butyl alcohol $(\mathrm{BuOH})$ to afford $\mathrm{CH}_{2} \mathrm{Cl}_{2}$ extract $(144 \mathrm{~g})$, EtOAc extract $(77 \mathrm{~g}), n-\mathrm{BuOH}$ extract $(105 \mathrm{~g})$, and $\mathrm{H}_{2} \mathrm{O}$ layer $(145 \mathrm{~g})$. The EtOAc extract $(77 \mathrm{~g})$ was first chromatographed over a silica ( $\mathrm{Si}$ ) gel column $(12 \times 60$, Silica gel 60, Merck, $2 \mathrm{~kg})$ and eluted with EtOAc-MeOH $(8: 1$ to $1: 1)$ to afford 14 fractions (Fr. 1-Fr. 14). A portion of fraction $1(430 \mathrm{mg})$ and fraction $2(300 \mathrm{mg})$ were acetylated with acetic anhydride-pyridine reagent and then purified by Si gel column chromatography with petroleum benzin-ether $(5: 1$ to $1: 1$, then with pure EtOAc) to give acetates of compounds 1 (1a) and 2 (2a). Finally, compounds $1(150 \mathrm{mg})$ and $2(170 \mathrm{mg})$ were obtained from compounds $1 \mathbf{a}$ and $\mathbf{2 a}$ by deacetylation. Fraction 3 $(7.53 \mathrm{~g})$ was subjected to column chromatography over a Si gel column with $n$-hexane-EtOAc $(1: 1$ to $\mathrm{MeOH})$ to give 9 fractions (Fr. 3-1 to Fr. 3-9). Subfraction 7 (Fr. 3-7, $1 \mathrm{~g}$ ) was further chromatographied with $\mathrm{CH}_{2} \mathrm{Cl}_{2}-$ $\mathrm{MeOH}$ on Si gel column to give 11 fractions (Fr. 3-7-1 to Fr. 3-7-11) and then subfraction 3 (Fr. 3-7-3, $244 \mathrm{mg}$ ) was purified by Sephadex LH-20 with $\mathrm{MeOH}$ to afford compound $3(40 \mathrm{mg})$. Fraction $14(4.76 \mathrm{~g})$ was chromatographed over $\mathrm{Si}$ gel using a EtOAc-MeOH $(30: 1$ to pure $\mathrm{MeOH})$ to obtain 9 fractions (Fr. 14-1 to 14-9). Fraction 4 (Fr. 14-4, 2.61 g) was repeatedly fractionated using a Sep-Pak cartridge (Waters, Sep-Pak PLUS C18), eluted with $\mathrm{H}_{2} \mathrm{O}-\mathrm{MeOH}(0,20 \%, 40 \%, 60 \%, 80 \%, 100 \% \mathrm{MeOH})$ to afford 6 fractions (Fr. 14-4-1 to Fr. 14-4-6). Fraction 4 (Fr. 14-4-4, 0.40 g) was repeatedly subjected to a Sep-Pak PLUS with $\mathrm{H}_{2} \mathrm{O}-\mathrm{MeOH}(0 \%, 10 \%, 30 \%$, 
$50 \%, 100 \% \mathrm{MeOH}$ ) to give 5 fractions (Fr. 14-4-4-1 to Fr. 14-4-4-5). Compound $4(33.7 \mathrm{mg})$ was isolated from subfraction 4 (Fr. 14-4-4-4, 50\% $\mathrm{MeOH}, 0.24 \mathrm{~g}$ ) by column chromatography on Si using $\mathrm{CH}_{2} \mathrm{Cl}_{2}-\mathrm{MeOH}$ ( $7: 1$ to $\mathrm{MeOH}$ ) as mobile phase. Fraction 8 (Fr. 14-8, $0.20 \mathrm{~g}$ ) was separated by Sephadex LH-20 with MeOH to afford 4 fractions (Fr. 14-8-1 to Fr. 14-8-4). Fraction 2 (Fr. 14-8-2, $160 \mathrm{mg}$ ) was consecutively purified, using a Sep-Pak cartridge, eluted with $\mathrm{H}_{2} \mathrm{O}-\mathrm{MeOH}(0 \%, 10 \%, 30 \%, 50 \%, 100 \% \mathrm{MeOH})$ to afford compound 5 (34.1 mg) from the $\mathrm{H}_{2} \mathrm{O}$ fraction (Fr. 14-8-2-1).

$2 \alpha, 3 \alpha, 24$-Trihydroxyurs-12-en-28-oic Acid (3): Amorphous white powder, HR-FAB-MS $m / z 511.3396\left[\mathrm{C}_{30} \mathrm{H}_{48} \mathrm{O}_{5}+\mathrm{Na}\right]^{+}$(Calcd for 511.3399), ${ }^{1} \mathrm{H}$ NMR data (pyridine- $d_{5}$ ) see Table $1 .{ }^{13} \mathrm{C}-\mathrm{NMR}$ data (pyridine- $d_{5}$ ) see Table 2.

$2 \alpha, 3 \alpha, 24$-Trihydroxyurs-12-en-28-oic Acid-28- $O$ - $\beta$-D-glucopyranosyl Ester (4): Amorphous white powder, HR-FAB-MS $m / z \quad 673.3925$ $\left[\mathrm{C}_{30} \mathrm{H}_{48} \mathrm{O}_{5}+\mathrm{Na}\right]^{+}$(Calcd for 673.3928), $[\alpha]_{\mathrm{D}}^{20}-25^{\circ}(c=0.08, \mathrm{MeOH}), \mathrm{IR}$ $(\mathrm{KBr}) \mathrm{cm}^{-1}$ : $3423,1735,1459,1074,1030,{ }^{1} \mathrm{H}-\mathrm{NMR}$ data (pyridine- $d_{5}$ ) see Table $1 .{ }^{13} \mathrm{C}-\mathrm{NMR}$ data (pyridine- $d_{5}$ ) see Table 2 .

$2 \alpha, 3 \alpha, 19 \alpha, 24$-Tetrahydroxyurs-12-en-28-oic Acid-28- $O$ - $\delta$-D-glucopyranosyl (5): Amorphous white powder, FAB-MS $m / z 689\left[\mathrm{C}_{36} \mathrm{H}_{58} \mathrm{O}_{11}+\mathrm{Na}\right]^{+}$, ${ }^{1} \mathrm{H}-\mathrm{NMR}$ data (pyridine- $d_{5}$ ) see Table $1 .{ }^{13} \mathrm{C}-\mathrm{NMR}$ data (pyridine- $d_{5}$ ) see Table 2.

Measurement of the ONOO$^{-}$Scavenging Activity The $\mathrm{ONOO}^{-}$scavenging activity was measured by monitoring the oxidation of DHR 123, by modifying the method of Kooy et al. ${ }^{13)}$ The DHR 123 (5 mM), in dimethylformamide, was purged with nitrogen, stored at $-80^{\circ} \mathrm{C}$ and used as a stock solution. This solution was then placed on ice, and kept from exposure to light, prior to the study. The buffer used consisted of $90 \mathrm{~mm}$ sodium chloride, $50 \mathrm{~mm}$ sodium phosphate, $5 \mathrm{~mm}$ potassium chloride, at $\mathrm{pH} 7.4$, and $100 \mu \mathrm{M}$ diethylenetriaminepentaacetic acid, each of which were prepared with high quality deionized water, and purged with nitrogen. The final concentration of the DHR 123 was $5 \mu \mathrm{M}$. The background and final fluorescent intensities were measured $5 \mathrm{~min}$ after treatment, both with and without the addition of authentic $\mathrm{ONOO}^{-}$. The DHR 123 was oxidized rapidly by authentic $\mathrm{ONOO}^{-}$, and its final fluorescent intensity remained unchanged over time. The fluorescence intensity of the oxidized DHR 123 was measured using a microplate fluorescence reader FL 500 (Bio-Tek Instruments Inc.), with excitation and emission wavelengths of 480 and $530 \mathrm{~nm}$, respectively. The results were expressed as the mean \pm standard error $(n=3$ or 5$)$ of the final flu- orescence intensity minus the background fluorescence. The effects were expressed as the percentage of inhibition of the DHR 123 oxidation.

Statistical Analysis All values were expressed as the mean \pm standard error of three or five replicate experiments.

Acknowledgments The FAB-MS spectra were provided by the Korea Basic Science Institute. This research was supported by a grant (PF032080100) from Plant Diversity Reasearch Center of 21st Century Frontier Research Program funded by Ministry of Science and Technology of Korean government.

\section{References}

1) Kritikar K. R., Basu B. D., "Indian Medicinal Plants," Vol. II, M/S Periodical Experts, New Delhi, 1974, p. 951.

2) Kim T. J., "Korean Resources Plants," Vol. II, Seoul National University Publisher, Seoul, 1996, p. 168-169.

3) Kim J. G., "Illustrated Natural Drugs Encyclopedia," Vol. I, Namsandang, Korea, 1997, p. 437.

4) Jung H. A., Kim A. R., Chung H. Y., Choi J. S., Arch. Pharm. Res., 25, $865-872$ (2002).

5) Takeoka G., Dao L., Teranishi R., Wong R., Flessa S., Harden L., Edwards R., J. Agric. Food Chem., 48, 3437-3439 (2000).

6) Sang S., Lapsley K., Rosen R. T., Ho C. T., J. Agric. Food Chem., 50, 607-609 (2002).

7) El Lahlou H., Hirai N., Tsuda M., Ohigashi H., Phytochemistry, 52, 623-629 (1999).

8) Fourneau C., Hocquemiller R., Cave A., Phytochemistry, 42, 13871389 (1996).

9) Jung H. A., Park J. C., Chung H. Y., Kim J., Choi J. S., Arch. Pharm. Res., 22, 213-218 (1999).

10) Chusheng H., Zhuangxin Z., Gansun L., Jun Z., Acta Botanica Yunnanica., 10, 93-100 (1998).

11) Kojima H., Tominaga H., Sato S., Ogura H., Phytochemistry, 26, 1107-1111 (1987).

12) Li B. Z., Wang B. G., Jia Z. J., Phytochemistry, 49, 2477-2481 (1998).

13) Kooy N. W., Royall J. A., Ischiropoulos H., Beckman J. S., Free Radical Biol. Med., 16, 149-156 (1994). 